\title{
Strain-Controlled Low-Cycle Fatigue Properties of a Newly Developed Extruded Magnesium Alloy
}

\author{
S. BEGUM, D.L. CHEN, S. XU, and ALAN A. LUO
}

DOI: $10.1007 / \mathrm{s} 11661-008-9722-\mathrm{z}$

(C) The Minerals, Metals \& Materials Society and ASM International 2008

Erratum to: METALLURGICAL AND MATERIALS

TRANSACTIONS A, Vol. 39, No. 12, December 2008,

pp. 3014-26

DOI: 10.1007/s11661-008-9677-0

FOLLOWING is the corrected version of Figure 8:

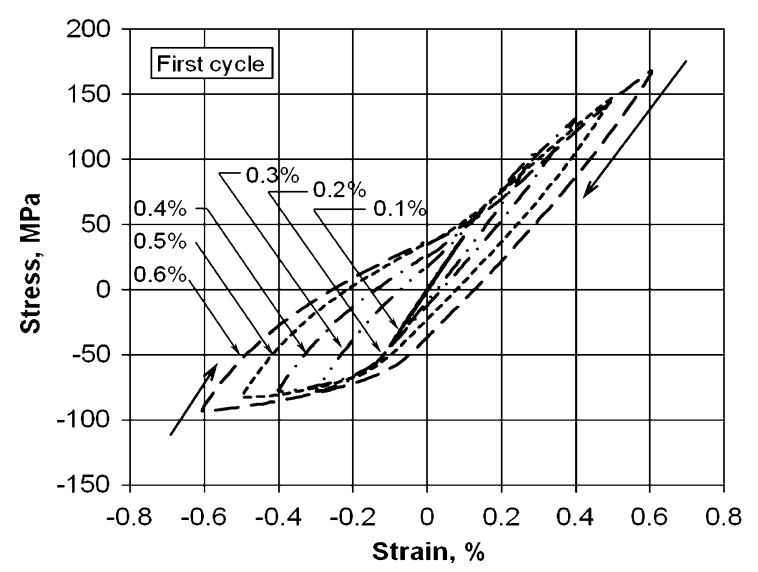

(a)

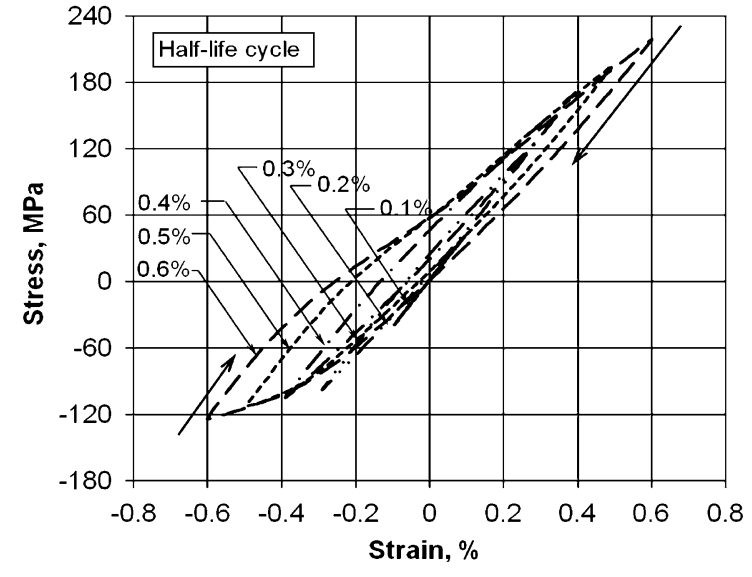

(b)

Fig. 8- Hysteresis loops (a) at first cycle and $(b)$ at half-life cycle for different total strain amplitudes.

S. BEGUM, Graduate Student, and D.L. CHEN, Professor and Ryerson Research Chair, are with the Department of Mechanical and Industrial Engineering, Ryerson University, Toronto, ON M5B 2K3, Canada. Contact e-mail: dchen@ryerson.ca S. XU, Research Scientist, is with CANMET-Materials Technology Laboratory, Natural Resources Canada, Ottawa, ON K1A 0G1, Canada. ALAN

A. LUO, Technical Fellow, is with the General Motors Research and Development Center, Warren, MI 48090.

The online version of the original article can be found under doi: 10.1007/s11661-008-9677-0.

Article published online November 8, 2008 